\title{
El discurso tecnopolítico de la gobernanza europea: un análisis crítico del discurso (ACD) de las políticas post-Lisboa ${ }^{1}$
}

\section{The Technopolitical Discourse of European Governance: a Critical Discourse Analysis (CDA) of the post-Lisbon Policies}

\author{
Francesco Maniglio ${ }^{2}$ \\ Centro Internacional de Estudios Superiores de \\ Comunicación para América Latina (Ecuador)
}

Recibido: 16-11-16

Aprobado: 26-02-17

\section{Resumen}

En las últimas dos décadas, en el proceso de gobernanza de la Unión Europea se ha ido debilitando progresivamente la importancia del sentido específicamente intelectual de la ideología, en favor de los procesos técnicos de resolución de problemas. Un cambio que podríamos denominar de desintelectualización de la hegemonía. El consenso no se genera en torno a una visión del mundo, sino más bien en relación a qué grupo particular tiene que ser responsable de la gestión administrativa de la UE. El discurso de la gobernanza, en consecuencia, ha desplazado su foco hacia modalidades que se desarrollan para hacer funcionar este policy making: las configuraciones institucionales devienen, necesaria y aparentemente, menos impositivas que en el pasado. La dirección tecnopolítica como capacidad de resolver los problemas

\footnotetext{
${ }^{1}$ El presente trabajo fue patrocinado por el proyecto Prometeo de la Secretaria de Educación Superior, Ciencia, Tecnología e Innovación (SENESCYT) de la Republica de Ecuador.

2 (franmgl@gmail.com) Es director de investigación del Centro Internacional de Estudios Superiores de Comunicación para América Latina (Ciespal) de Ecuador. Es doctor en Comunicación y Crítica de la Cultura por la Universidad de Sevilla, master en Filosofía del Derecho por la Universidad Pablo de Olavide. Es asociado al grupo de investigacion Compoliticas de la Universidad de Sevilla y al Laboratorio de Estudios Críticos del Discurso (Labec) de la Universidad de Brasilia. Entre sus últimas publicaciones destacamos El gobierno del General Intellect (Ed.Ciespal, 2016); To lead without governing in the knowledge society (Discourse and Society, 2015).
} 
-y coordinar a la sociedad - es contextualmente una gestión política mediada, dada su capacidad de mando. En efecto, se otorga la dirección a actores que no se presentan como parte de la clase dominante, sino como intelectuales, profesionales de la política -administradores-, que sólo indirectamente comparten la defensa de los intereses del corporativismo europeo que, de esta forma, se siguen representando como intereses más bien comunes.

Palabras-clave: Ideología, Gobernanza Europea, Políticas Europeas, Análisis Crítico del Discurso, Discurso tecnopolítico.

\begin{abstract}
Over the last decades, the process of governing in the EU has gradually weakened the importance of the intellectual sense of the ideology, in favour of the technical processes of problem solving. A shift we could call unintellectualization of the hegemony. An agreement is no longer sought on a vision of the world, but rather on which group is to become responsible for the administrative management of the EU. The discourse of governance, therefore, has focused on the process of this policy making: institutional settings become necessary and apparently less stringent than in the past. The direction of technopolitics, intended as the ability to solve problems of the society, involves the capacity to domain. The legitimacy is given to actors that do not present themselves as part of the dominant class, but as intellectuals, technicians, political professionals (administrators), that indirectly share the defence of the European corporatism's interests, which continue to be presented as the common interests.
\end{abstract}

Key-words: Ideology, European Governance, European Policies, Technopolitical Discourse, Critical Discourse Analysis.

\title{
Introducción
}

En este análisis distinguimos el proceso de re-orientación que se afirma con la tecnocratización de los Estados, un cambio que no se refiere solo a los aspectos organizacionales o a las capacidades de gobernanza, sino también a los aspectos ideológicos y de racionalización (Radaelli, 1999a; 1999b; 2000). Tomando como referencia el estudio histórico propuesto por Fisher (1990), queremos contribuir a la descripción de aquellas modalidades según las cuales los tecnócratas continúan ganando poder, aunque a la sombra de las estructuras formales, insinuándose profundamente en el surco de los valores y las instituciones democráticas desde las cuales operan. Lo que Dingwerth define como gobernanza global, en tanto 
que proceso político mundial (Dingwerth \& Pattberg, 2006), se beneficia de una poderosa línea ideológica y organizativa, gracias a diversas actividades llevadas a cabo, en primer lugar, a través de los advisory boards (Boston, 1988), think tanks (Fischer \& Forester, 1993), angencias reguladoras (Majone, 1996), universidades e institutos de investigación que intervienen en la creación, organización y gestión de las nuevas agendas políticas. En términos políticos, se ha ido formando unas alianzas inter-oligárquicas (Balsa, 2006) que marcan una fase histórica en la cual la hegemonía neoliberal se articula eliminando de su base las cuestiones de gran política (Coutinho, 2011), en las discusiones entre republicanos y demócratas en EEUU, laboristas y conservadores en el Reino Unido, centro-derecha y centro-izquierda en Italia, socialistas y populares en España. Se desarrolla un bipolarismo técnico que, en cuanto tal, no presenta ninguna alternativa entre modelos diferentes de sociedad, porque el papel de los partidos políticos, en general, en el proceso de toma de decisiones contemporáneo, ha dejado el paso al papel de los grupos de expertos en el ámbito de la administración. La hipótesis que sostiene Coutinho es que en esta hegemonía no se presentan los rasgos de una revolución pasiva, sino los de una contrarreforma: mientras en la primera estarían en juego las cuestiones y las disputas de la gran política, en la segunda los eventuales conflictos no van más allá de los límites de la pequeña política. Esto deviene posiblemente porque la sustancia de los acuerdos políticos se substraen por el síndrome del corto-plazo de las élites políticas elegidas en este bipolarismo, a través de la violación constante del principio mayoritario. Podemos observar un cambio de papel de los gobiernos locales en su forma de intervenir en la toma de decisiones: se quedan con la administración de la pequeña política (Coutinho, 2011) -o sea se limitan a la "solución de problemas intermedios" respecto a procesos ya establecidos. Sin embargo siguen siendo determinantes al no encontrarse en antinomia respecto al centralismo, sino en co-acción con un sistema más parecido al denominado directly deliberative polyarchy (Gerstenberg \& Sabel, 2002) 3 $^{3}$ Concretamente, nos encontramos en las dinámicas de cambio que se realizan en la misma naturaleza del poder, con los conocimientos y el expertise que devienen el territorio de la política y con una repolitización de la esfera pública. El discurso de la gobernanza, en consecuencia, ha desplazado su foco hacia modalidades que se desarrollan para hacer funcionar estas elaboración de políticas y las configuraciones institucionales que son, necesaria y aparentemente, menos impositivas que en el pasado. El corolario es una mentalidad más preocupada por el progreso tecnológico, la eficiencia y la productividad de los materiales que por la equidad y la justicia social.

\footnotetext{
3 Se trata de un proceso directly deliberative porque los actores locales están directamente envueltos; y es polyarchic porque, aunque limitados en el ejercicio del poder decisorio (que solo formalmente las democracias representativas les otorga), siguen quedando accountable respecto a la opinión pública.
}

Araucaria. Revista Iberoamericana de Filosofía, Politica y Humanidades, año 19, n 37 . Primer semestre de 2017. Pp. 327-351. ISSN 1575-6823 e-ISSN 2340-2199 doi: 10.12795/araucaria.2017.i37.16 
Las leyes en temas de políticas fiscales, nuevas regulaciones de las finanzas, reformas del mercado del trabajo, privatización de los bienes comunes (educación, agua, salud, transportes...), emanadas en diferentes países desde los años ochenta, y que ahora el Fondo Monetario Internacional (FMI), el Banco Central Europeo (BCE) y la Comisión Europea (CE) quieren imponer sin excepción alguna a todos los miembros de la Unión Europea - $\mathrm{O}$ cuando menos a los que forman parte de la eurozona- representan una parte privilegiada de las modalidades a la que nos estamos refiriendo. Tras las últimas tres décadas, en efecto, con la difusión del saber en las dinámicas del progreso técnico y en la organización productiva, los economistas, los políticos, los científicos, así como gran parte de la sociedad civil e intelectual convienen que el conocimiento y la tecnología, sobre todo la comunicativa, se han impuesto de forma ineluctable, como componentes fundamentales para el crecimiento económico. Desde la perspectiva crítica (González de Requena Farré, 2010; Innerarity, 2011; Maniglio, 2015; Matsuura, 2005; Mattelart, 2006; Restakis, 2015; Rubio, 2003; Serrano \& Crespo, 2002; Sierra Caballero, 2006) hay que rescatar cómo este "hecho indiscutible" - esta incontestable noción de sociedad como una acción político-económica-determina nuevas experiencias del mundo, transformaciones y problemáticas sociales. Los antagonismos capital-trabajo y los conflictos políticos inmanentes a este desarrollo de la relación saber/poder (Vercellone, 2006a), en efecto, se dirigen gracias a un sistema de gobernanza comunitario (Kim, 2004), caracterizado por una alianza tecno-científica que tiende a favorecer la convergencia de los proyectos de Sociedad de la Información y del Conocimiento con teorías y producciones científicas como las del Crecimiento Endógeno, del Capital Humano, de las competencias sociales y de la Economía del Conocimiento (Maniglio, 2016). En otros términos, no obstante que las élites políticas guardan el poder en el proceso decisional, tienden a justificar siempre más constantemente sus decisiones remitiéndose a los análisis técnicos de los expertos con los cuales forman una especie de coalición ${ }^{4}$. La comunidad epistémica (Radaelli, 1999c), junto con los lobbies industriales y financieros, definen en la UE el tecno-corporativismo (Fischer, 1990) que interviene prepotentemente en la concepción, construcción y aprobación de las políticas públicas de las últimas décadas. En efecto, "este grupo medular es una alianza de varias fracciones de diferentes grupos sociales y de interés que constituyen la población" (Grossberg, 2005, p. 54). Cartográficamente se nota un entrelazamiento de los actores europeos y nacionales en el sistema comitólogo ${ }^{5}$ con una red de

\footnotetext{
${ }^{4}$ Fischer (1990) identifica esta etapa en términos de politics of expertise, o sea como una estricta unión que se realiza entre las élites tradicionales y los tecnócratas capaces de producir una mutua y conveniente estrategia.

${ }^{5}$ Como un marco para la generación de normas, la comitología parece ser una respuesta menos idiosincrásica respecto al problema de la integración de regulación de la UE, y más una instancia clave 
agencias en la administración y legislación de la UE. Se establece el modus operandi de resolución de problemas, marcado por el fortalecimiento de la interacción pública-privada (tecnocorporativismo). Todo eso sin que sea fácilmente identificable una clara jerarquía de poder y competencias en cada parte de este proceso (Rosenau \& Czempiel, 1992). Se van transformando, de este modo, las formas de legitimación en tanto que ya no se definen en los términos de representación política o identidad común, como era en el caso de los estados nacionales. Faltando así los presupuestos de una input legitimacy ${ }^{6}$, el tecnocorporativismo se ha centrado en la construcción de unas formas de legitimidad que ponen en el centro de la atención pública una serie de resultados técnicos predefinidos. Los procesos discursivos de la gobernanza europea son parte de estas relaciones de legitimación: se vuelven tecnopolíticos en la medida en que se desplaza el foco hacia modalidades que se desarrollan para hacer funcionar la elaboración de políticas y las configuraciones institucionales que son, necesaria y aparentemente, menos impositivas que en el pasado.

\section{El discurso tecnopolítico como proceso de construcción de la legitimidad}

Sostener un discurso tecnopolítico al interior de la gobernanza europea no significa que hayamos renunciado al análisis ideológico, ni tampoco que vivamos en un horizonte post-ideológico. Significa que el "mero campo intelectual" no resuelve la disputa hegemónica, especialmente en el seno de la gobernanza de los Estados del capitalismo avanzado, donde los campos ideológicos se instituyen sobre la base de un amplio pluralismo; incluso abundan en concepciones críticas y se cooptan posturas subalternas?

[Ha ocurrido una] degradación de la esfera pública, en la que la manipulación simbólica ha reemplazado al debate y el esclarecimiento de las opiniones se ha

para una amplia reorientación de la legislación. A pesar de que los actores y los ámbitos de actuación pueden estar distantes, el sistema comitológico permite que la arquitectura institucional de la toma de decisiones se constituya con una fuerte afinidad de hecho (Gerstenberg y Sabel, 2002, p. 325).

${ }^{6}$ Algunos analistas (Scharpf, 2000; 1999; 1997; Marks et al., 1996), suelen distinguir entre dos formas de legitimidad, según que sea determinada por una forma pre-existente de legitimidad de la comunidad en estudio (input legitimacy) o por los resultados conseguidos a través de la misma comunidad política (output legitimacy).

${ }^{7}$ Así pues, el tecnocorporativismo tiene que estar socialmente autorizado para ejercer su función política, debe tener una determinación parcialmente externa si lo pensamos (en términos analíticos) como un campo específico (necesita de un reconocimiento externo). Significa que no puede ignorar ni eliminar a la conflictividad social. Cada grupo o fuerza competitiva, cada forma o acto de resistencia, cada grupo que se articula con la gobernanza europea en acto o que ofrece una visión alternativa para la sociedad, o una definición alternativa de los problemas, o una solución alternativa a un problema particular. Y, en efecto, negocia con los elementos de la resistencia y la oposición, haciendo espacios (discursivos y no) para aquellas visiones competitivas y fuerzas sociales antagonistas. En lugar de tratar de desarmarlas completamente, el tecnocorporativismo asume en su unidad algunas de ellas; puede incluso acomodarse a ellas y hacerles concesiones. 
rebajado a un problema técnico que deben resolver los expertos en propaganda y en relaciones públicas. En un sentido, las ideologías se han autonomizado; pero esto al precio de irse disolviendo como tales, es decir, como modos racionales de discurso. (Nun, 1989, p. 44-45)

El discurso tecnopolítico - en una definición amplia del nivel ideológicose expresa y tiene lugar de un modo inevitable a través y en el lenguaje: esta es la cuestión central que abordaremos en este apartado. Si bien podemos distinguir entre prácticas discursivas y prácticas no discursivas - por los modos históricos que toman sus lógicas de acción- las primeras también llevan un cuerpo material y una vertiente política, tienen consecuencias concretas y propias, por lo que son claramente actuantes. Esto implica pensar el discurso tecnocorporativo no en su aparente carácter etéreo, sino en los efectos históricos de la interacción social, como una práctica concreta para la legitimación de una particular dirección política. La idea de dominante cultural (Jameson, 1991) en el contexto coyuntural post-Lisboa nos sitúa lejos de una dimensión natural o absoluta de las relaciones económicas y políticas; más bien dentro de una serie de relaciones dialécticas producidas en el proceso hegemónico: ante unos contenidos específicos de acción, producidos por alianzas de clases en las que estamos orgánicamente situados.

Bajo estas convicciones, adoptamos la técnica del ACD con la idea de analizar cómo el tecnocorporativismo produce y reacciona con los significados particulares que se articulan en las construcciones discursivas. Esta relación dialéctica que reviste gran importancia en términos de relaciones de poder, ya que el control sobre los tipos de discurso por parte de los detentores del poder político es un factor fundamental para la reproducción del mismo (Franquesa Strugo, 2002).

La premisa fundamental en esta perspectiva de la teoría de la praxis es renunciar a toda pretensión metafísica y trascendental para definir el concepto de discurso ${ }^{8}$ (Ruiz \& Sylvia, 2005), al estar determinado por convenciones asociadas a las instituciones sociales, las que, al mismo tiempo, son modificadas por el propio discurso.

\section{Delimitación y Selección del Corpus}

La ventaja de relacionar el ACD con la Economía Política del Conocimiento consiste propiamente en la adopción de un enfoque que subraye el discurso tecno-corporativo como una reacción particular, un momento particular de

\footnotetext{
${ }^{8}$ Mijail Bajtín y Valentín Voloshinov han propuesto una filosofía del lenguaje que deconstruye dialécticamente las corrientes linguísticas del subjetivismo abstracto (Wilhelm Humboldt) y del objetivismo abstracto (Ferdinand de Saussure).
} 
las prácticas sociales (Chouliaraki \& Fairclough, 1999), sin que perdamos de vista la relación dialéctica entre el momento discursivo y otros momentos nosemióticos que intervienen en los procesos hegemónicos.

Los discursos de European Round Table ${ }^{9}$ y de la Comisión y Consejo de la UE, son representaciones particulares, partes del nivel coyuntural de las prácticas sociales, mientras que los textos escogidos se localizan como momentos significativos respecto al objetivo de analizar el proceso de producción ideológica de la gobernanza europea. Hemos seleccionado la muestra en base a periodos diferentes y definidos (textos producidos en años similares), a las temáticas tratadas (las políticas desde la Sociedad de la Información/ Conocimiento, ICT, educación y empleo), y a la importancia coyuntural (política, social y relacional) en el estado de correlación de fuerzas de la presente década. Con estos criterios, hemos elegido cuatro informes (dos producidos por ERT y dos producidos por la Comisión Europea) de importancia estratégica en cuanto marcan la puesta en marcha de planes de ajustes estructurales decenales con el objetivo de desarrollar la economía del conocimiento en la UE.

\section{Tabla I}

\begin{tabular}{|c|c|c|c|c|}
\hline \multicolumn{5}{|c|}{ Corpus seleccionado } \\
\hline Año & Autor/Autores & Tipo de Autor/Autores & Texto seleccionado & Id. del texto \\
\hline \multirow[b]{2}{*}{$\begin{array}{l}2000 \\
/ 2001\end{array}$} & Consejo Europeo & Institucional/gubernativo UE & $\begin{array}{l}\text { Conclusiones de la Presidencia: Consejo Europeo de } \\
\text { Lisboa: } 23 \text { y } 24 \text { de marzo de } 2000\end{array}$ & (UE 2000) \\
\hline & ERT & $\begin{array}{l}\text { Institucional/grupo de presión } \\
\text { politica de las multinacionales } \\
\text { de Europa }\end{array}$ & $\begin{array}{l}\text { Actions for Competitiveness Through the Knowledge } \\
\text { Economy in Europe: Message from the European Round } \\
\text { Table of Industrialists to the Stockholm European } \\
\text { Council, March } 2001\end{array}$ & (ERT 2001) \\
\hline \multirow{2}{*}{2010} & $\begin{array}{l}\text { Comisión de las } \\
\text { Comunidades } \\
\text { Europeas }\end{array}$ & Institucional/gubernativo UE & $\begin{array}{l}\text { EUROPA 2020. Una Estrategia para un crecimiento } \\
\text { inteligente, sostenible e integrador }\end{array}$ & (UE 2010) \\
\hline & ERT & $\begin{array}{l}\text { Institucional/grupo de presión } \\
\text { política de las multinacionales } \\
\text { de Europa }\end{array}$ & ERT's Vision for a competitive Europe in 2025 & (ERT 2010) \\
\hline & del auto & & & \\
\hline
\end{tabular}

\footnotetext{
${ }^{9}$ ERT es un foro que reúne a los directores ejecutivos y presidentes de las empresas multinacionales europeas más grandes que cubren una amplia gama de industriales de los sectores tecnológicos. Las empresas miembros de la ERT se encuentran en toda Europa, donde son líderes, con ventas superiores a los mil millones de euro, con una tasa de empleo alrededor de 6,6 millones de puestos de trabajo en la región. En general, la contribución de las empresas miembros ERT al PIB de la UE es superior al de 21 de los 27 Estados miembros de la UE
} 


\section{Las dimensiones ideacionales del discurso tecnopolítico}

Los cambios en la dimensión de la ideación del discurso se construyen con varias tipologías de procesos codificados con diferentes participantes envueltos en las mismas. La sintaxis es uno de los medios más evidentes para expresar las opiniones ideológicas sobre acontecimientos, personas y participantes, ya que al igual que las palabras aisladas, las estructuras gramaticales también presentan valor experiencial, relacional y expresivo (Fairclough, 1989; T. Van Dijk, 1999) ${ }^{10}$. Consideramos tres tipologías de procesos: las acciones (SVO), los eventos (SV) y las atribuciones (SVC) (Fairclough, 1989, p. 122). Con el análisis de la transitividad, aportamos información fundamental al proceso discursivo del tecnocorporativismo europeo: precisamente podemos determinar quiénes son los participantes elegidos para protagonizar la acción; qué tipos de fenómenos ejecutan distintos actores; y a quiénes se les atribuye mayor poder.

\section{El cambio económico global}

Entre finales de la década de los noventa y principio del 2000, bajo los auspicios de un cambio económico global, la gobernanza europea implementaba el proceso de europeización, con la traslación de muchos poderes decisorios al professional expertise a través de procedimientos que no garantizan transparencia, representación y participación democrática "clásica".

Con el Consejo Europeo de Lisboa (UE, 2000) el cambio económico se constituye, en efecto, en un evento universal (mundialización), en una contienda (desafíos) sin contendientes. La Unión Europea es el agente inanimado ${ }^{11}$ (verbo reflexivo) de un proceso inevitable (se enfrenta) en respuesta a un evento sobrenatural (un enorme cambio).

La Unión Europea se enfrenta a un enorme cambio fruto de la mundialización y de los desafíos que plantea una nueva economía basada en el conocimiento" (IIUE 2000> Referencia 1).

Estos procesos se mistifican en cuanto no se vinculan a algunas agencias humanas (dichos cambios), aunque su acción no sólo interviene (afectan) en la sociedad (los ámbitos de la vida de las personas), sino que se imponen (exigen),

${ }^{10}$ Los aspectos experienciales de la gramática se constituyen como dimensiones ideacionales que, en el análisis de nuestro corpus, tienen que ver con la forma en que una lengua codifica los acontecimientos o relaciones, incluyendo a los participantes involucrados, sus circunstancias, forma de ocurrencia, etc. Esta codificación puede entenderse en términos funcionales como la representación lingüística de procesos de acciones, eventos y atribuciones (Halliday 1985; Halliday \& Hasan 1991; Lirola 2007).

${ }^{11}$ Las acciones, también llamadas procesos materiales, son estructuras que tienen la forma S-V-O [sujeto-verbo-objeto], por lo que involucran a dos participantes, uno actuando con el otro. Estos participantes, categorizados como agentes, pueden ser animados o inanimados.

Araucaria. Revista Iberoamericana de Filosofía, Política y Humanidades, año 19, n 37. Primer semestre de 2017. Pp. 327-351. ISSN 1575-6823 e-ISSN 2340-2199 doi: 10.12795/araucaria.2017.i37.16 
en términos normativos, con las agendas económicas (transformación radical de la economía europea).

Dichos cambios afectan a todos los ámbitos de la vida de las personas y exigen una transformación radical de la economía europea (IVUE 2000> Referencia 2).

La Unión Europea se constituye como un agente actuante respecto a la potencia de los eventos. Eventos que, en la oración sucesiva, devienen agentes/causantes (dichos cambios) de unos procesos que van a afectar a la sociedad en su totalidad: se construye la subordinación de la Europa Política respecto a las fuerzas económicas internacionales. Esta jerarquización, como disposición ideacional legitimante, es bastante evidente también en las primeras macroproposiciones del informe de ERT (2000):

Los europeos están en el proceso de construir una nueva Europa sobre las bases de una mejor competitividad y una economía dinámica basada en el conocimiento (IIERT 2000> Referencia 1).

Esta economía se extenderá finalmente hacia un grupo significativamente más grande que los quince miembros que actualmente conforman la Unión Europea (IVERT 2000> Referencia 2).

Se marca así un evento concreto: se construye el agente de forma incluyente y consensual (los europeos), actuando en un proceso existencial (están en el proceso de construir), y por tanto indiscutible, para conseguir una meta (nueva Europa) con unos medios coercitivos (sobre las bases de una mejor competitividad y una economía dinámica basada en el conocimiento).

En la oración siguiente, el medio se transforma en agente/causante (economía) que marca un proceso material (extenderá) respecto al paciente (un grupo significativamente más grande que los quince miembros que actualmente conforman la Unión Europea).

Sin embargo, en 2010 el contexto coyuntural evoluciona notablemente ${ }^{12}$ y las diferencias de accountability, en las diversas fuerzas que componen el tecnocorporativismo europeo, se ponen de manifiesto también en las prácticas discursivas. La Comisión Europea en Europa 2020 (UE, 2010) ya no legitima su nueva agenda política en un indeterminado cambio económico mundial, sino sobre la base de un -aún más indeterminado- momento de transformación.

Europa se enfrenta a un momento de transformación (IIUE 2010> Referencia $1)$.

12 "La reciente crisis económica no tiene precedentes en nuestra generación. Los constantes progresos en materia de crecimiento económico y creación de empleo registrados durante la última década han desaparecido" (UE 2010). 
Este momento de transformación, en realidad, se constituye siempre como un evento universal ineluctable: un evento sobrenatural al cual la Unión, como único agente, tiene que responder (se enfrenta). En la oración siguiente, el evento deviene agente inanimado (La crisis) responsable (ha echado - expuesto) del contexto crítico (las debilidades estructurales de la economía europea).

La crisis ha echado por tierra años de progreso económico y social y expuesto las debilidades estructurales de la economía europea. Mientras tanto, el mundo se mueve con rapidez y los retos a largo plazo (mundialización, presión sobre los recursos, envejecimiento) se intensifican (IIUE 2010> Referencia 2).

De esta forma se obvia determinar el responsable directo de una acción (agente), favoreciendo que cualquiera pueda ser sindicado como responsable, aún cuando no lo sea. Se transforman las acciones en eventos, así como la lectura de los hechos como algo natural y tal vez inevitable. Por otro lado, ERT en su informe (ERT, 2010) obvia la legitimación de su propuesta político-económica en términos de eventos críticos, proyectando directamente su acción hacia un futuro distinto, pero indeterminado: un proceso hacia un futuro general, mal definido y sin historia (esto es sólo lo que "será").

En el 2025, el mundo será muy distinto a como es en la actualidad" (IVERT 2010> Referencia 1).

En esta oración, los industriales construyen un proceso existencial, involucrando un agente inanimado (el mundo) y a continuación del proceso verbal (será) un atributo. Con este atributo (muy distinto a como es en la actualidad) se legitiman toda una serie de acciones (agendas políticas) que se explicitan en la prosecución del texto.

\section{La visión del mundo tecnho-corporativo}

Desde la perspectiva de la retórica estas oraciones contribuyen a la instauración del ethos del tecnocorporativismo europeo. En los textos de la Comisión y del Consejo $(2000 ; 2010)$, con los procedimientos enunciativos "La Unión Europea se enfrenta (...)" se construye el ethos de la potencia o del poder, que se expresa por medio de la fuerza verbal contra un contexto adverso, crítico o particular, mostrándose como el único agente propuesto y competente para la acción. En los textos de ERT (2000), con el procedimiento enunciativo "Los europeos están en el proceso de construir (...)" se cimienta el ethos de la virtud y de la competencia, ampliando también el colectivo de identificación con la referencia al nosotros inclusivo (los europeos). Entretanto, con el procedimiento enunciativo "el mundo será muy distinto a como es (...)" (ERT, 
2010), el enunciante utiliza la modalidad del saber (será, es), demostrando su capacidad para evaluar determinadas situaciones y decidir así acciones futuras (ethos de inteligencia). Los verbos creer o saber, propios de la modalidad epistémica, se combinan con otros característicos de la modalidad volitiva: querer, esperar, desear. Con estos últimos, la Comisión (2010) quiere instaurar el ethos de humanidad (con la capacidad de reflejar y expresar sentimientos y debilidades) en relación la crisis (y a nueva capacidad de generar consenso) de las instituciones europeas en el contexto político-social marcado por la crisis económica:

Debemos tomar medidas si queremos que nuestra generación y las generaciones venideras puedan seguir disfrutando de una vida de alta calidad y sana, sostenida por el modelo social único de Europa (IIUE 2010> Referencia 2).

Estos objetivos son representativos, no exhaustivos. Representan una visión general del lugar en donde la Comisión desearía que se situaran los parámetros clave de la UE en 2020 (IIUE 2010> Referencia 4).

Sin duda es la modalidad deóntica, asociada a la idea del deber u obligación, a ser predominante. Un deber que no es sólo de los emisores sino de todos los europeos. El tecnocorporativismo europeo se compromete respecto a la verdad y a la necesidad de lograr el consentimiento de la ciudadanía. El ethos de la virtud y de la competencia la ubican no sólo en el lugar de saber, sino también de poder hacer efectivas las medidas propuestas:

Las presiones de competitividad de la globalización hacen que la tarea de construir una Economía del Conocimiento sea urgente. En particular, los objetivos planteados en Lisboa deben de ser respetados e implementados (IVERT 2000> Referencia 1).

Hay mucho que se puede hacer para acelerar y fomentar la transición de poblaciones enteras utilizando la vía electrónica para llevar servicios e información pública (IVERT 2000> Referencia 4).

La UE sólo puede hacer frente a los retos del futuro y seguir siendo un lugar atractivo para vivir y trabajar (...). En el 2025, la estructura de gobierno de la UE y el proceso de toma de decisiones deben ser más eficientes, más transparentes y más democráticos (IVERT 2010> Referencia 2).

Debe hacerse lo necesario para que Europa mantenga su posición de vanguardia en ámbitos tecnológicos clave, tales como las comunicaciones móviles. (IIUE 2000> Referencia 2). 
Este enfoque de colaboración debería extenderse a los comités de la $\mathrm{UE},(\ldots)$ con el fin de que todos podamos aportar algo a la consecución de los objetivos (\UE 2010> Referencia 2).

\title{
El contexto del riesgo
}

Las relaciones adversativas en este caso marcan cuestiones de sentido adicional que podemos identificar como presuposiciones. Estas estrategias determinan la voluntad para realizar la acción por medio de refutaciones sofistas, o sea "formas argumentales que poseen una falsa apariencia de racionabilidad" (Van Eemeren, 1997, p. 217). En el texto de la UE de 2000, los conectores cohesivos adversativos contribuyen a construir una presuposición constante de contextos de riesgos, determinando de esta forma la acción (función deóntica) para no incurrir en dichos riesgos. Vemos un ejemplo de este caso:

\begin{abstract}
3. La Unión está experimentando sus mejores perspectivas macroeconómicas en una generación. Como resultado de una política monetaria orientada a la estabilidad y apoyada por políticas fiscales sólidas en un contexto de moderación salarial, los índices de inflación y los tipos de interés son bajos, los déficit públicos se han reducido notablemente y la balanza de pagos de la UE es sana. El euro se ha introducido con éxito y está dando los beneficios esperados a la economía europea. El mercado interior se ha culminado prácticamente y está produciendo beneficios tangibles tanto para los consumidores como para las empresas. La próxima ampliación creará nuevas oportunidades de crecimiento y empleo.(...)

4. No obstante, dichos puntos fuertes no deben impedirnos ver algunos puntos débiles. Más de quince millones de europeos carecen todavía de empleo. El índice de empleo es demasiado bajo y se caracteriza por una participación insuficiente de las mujeres y de los trabajadores de edad más avanzada en el mercado laboral. En algunas partes de la Unión siguen siendo endémicos el desempleo estructural de larga duración y fuertes desequilibrios regionales de desempleo. (...) (IIUE 2000> Referencia 1).
\end{abstract}

La presuposición de un contexto de riesgo o de preocupación, tanto económica como social, es una estrategia frecuentemente utilizada con la finalidad de construir el consenso a través de la constitución del ethos de la competencia y de la virtud del enunciador. Vemos otro ejemplo referido al texto de 2010:

- La tasa media de crecimiento de Europa ha sido estructuralmente inferior a la de nuestros principales socios económicos, en gran medida debido a una diferencia de productividad que aumentó durante la pasada década. Gran parte de ello se debe a diferencias en las estructuras empresariales, junto con menores 
niveles de inversión en investigación, desarrollo e innovación ( + +D+i), un uso insuficiente de las tecnologías de la información y la comunicación (TIC), la reticencia de determinados sectores de nuestras sociedades a acoger la innovación, obstáculos para el acceso al mercado y un entorno empresarial menos dinámico.

- A pesar de haber mejorado, los niveles de empleo en Europa (media del $66 \%$ para las personas de 20-64 años) todavía son perceptiblemente más bajos que en otras partes del mundo: solo el $63 \%$ de las mujeres trabajan, en comparación con un $76 \%$ de los hombres, y solo el $46 \%$ de los trabajadores más mayores (55-64 años) tienen un empleo, en comparación con más del $62 \%$ en Estados Unidos y Japón. Por otra parte, el europeo medio trabaja un $10 \%$ de horas menos que su equivalente estadounidense o japonés (IIUE 2010> Referencia 2).

En los ejemplos arriba mencionados, si proyectamos los primeros períodos en una estructura de contrariedad, dividida por las locuciones "no obstante" y "a pesar de", notaremos cómo en cada uno de los casos se determina la función deóntica gracias a la creación de dos contextos contrarios: uno de riesgo que resigna antes al acto, y uno de no riesgo que determina la voluntad para realizar la acción.

\section{La resolución de los problemas (La función deóntica del tecnho-corporatism)}

En segundo lugar, las funciones epistémicas y deónticas son formas relativamente estables de actuar y de relacionarse en prácticas sociales y, por lo tanto, se construyen también mediante géneros discursivos situados (Ramalho $\&$ Resende, 2011). Los géneros discursivos envuelven directamente: actividad, personas y lenguaje; mientras que los modos de interacción, implican actividades específicas ligadas a prácticas particulares. De modo que cada actividad social posee una meta intencional y una función específica.

En este sentido nos preguntamos: ¿cuáles son las actividades discursivas que un grupo específico está ejerciendo y con qué función o propósito? Estos propósitos se materializan en los textos con lo que hemos definido como estructura genérica; es decir, un aspecto textual moldeado por géneros discursivos (Ramalho \& Resende, 2011, p. 122-123). La estructura genérica de las Conclusiones del Consejo de Lisboa (2000) corresponde a la organización y a la materialización de propósitos bien precisos por parte de la gobernanza europea. Se construye mediante una estrategia de inter-genericidad que, en un nivel macro, podemos identificar con el género instructivo, consistente en dar instrucciones, consejos, normas al receptor: se divide en párrafos de ideas temáticas explícitas, que remarcan las funciones deónticas del discurso. Estas ideas conforman macro-proposiciones numeradas (56) que reflejan 
un significado propio y cumplido ${ }^{13}$. La sección I. EMPLEO, REFORMA ECONÓMICA Y COHESIÓN SOCIAL delimita nuestra muestra. En esta sección podemos identificar una secuencia argumentativa (género argumentativo) que marca la función epistémica del discurso, consistente en la defensa de una posición teórico-política mediante razonamientos que pretenden convencer. Sin embargo, dentro de un texto argumentativo como es el caso en cuestión, hay secuencias textuales descriptivas (consisten en explicar o dar a conocer las características de un proceso que persigue un determinado fin, que se alcanzará al seguir unos pasos).

\section{Gráfico 1}

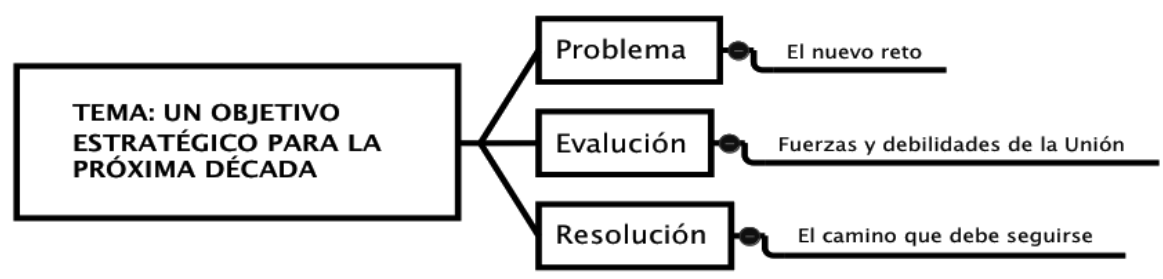

En este caso, la secuencia descriptiva es también expositiva, es decir interviene en el desarrollo del tema y de las ideas. Este es el género de los ensayos científicos: se distingue la función epistémica, cuyo objeto principal es expresar información o ideas con la intención de mostrar y explicar o hacer más comprensibles dichas informaciones, y la función deóntica, que propone una resolución con base en la problemática expuesta.

El mensaje de ERT Acciones para la competitividad a través de la Economía del Conocimiento en Europa (2001) se construye a nivel macro con una secuencia argumentativa que marca la función epistémica del discurso:

${ }^{13}$ El texto se divide en varias secciones macro-temáticas:

I. EMPLEO, REFORMA ECONÓMICA Y COHESIÓN SOCIAL

II. POLÍTICA EUROPEA COMÚN DE SEGURIDAD Y DEFENSA

III. BALCANES OCCIDENTALES

IV. RUSIA

V. CONFERENCIA INTERGUBERNAMENTAL

VI. REGIONES ULTRAPERIFÉRICAS

Araucaria. Revista Iberoamericana de Filosofía, Política y Humanidades, año 19, nº 37. Primer semestre de 2017. Pp. 327-351. ISSN 1575-6823 e-ISSN 2340-2199 doi: 10.12795/araucaria.2017.i37.16 


\section{Gráfico 2}

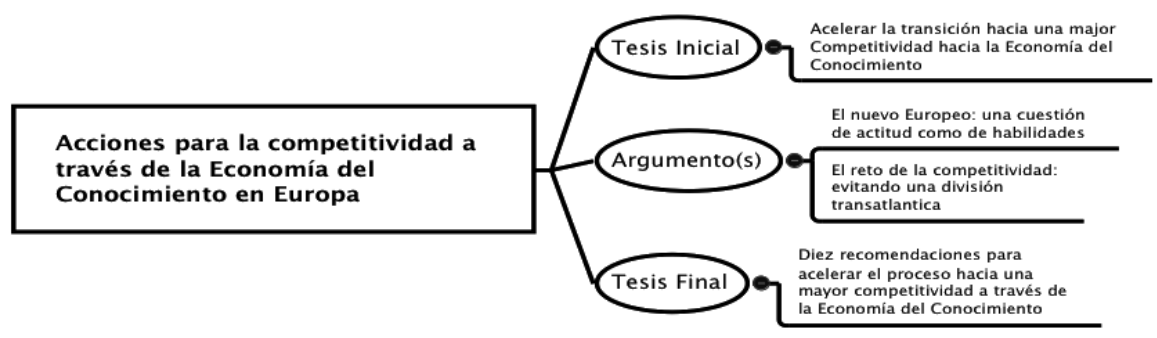

Para enfatizar esta función, las primeras dos partes de la secuencia argumentativa son compuestas por una secuencia expositiva (género expositivo); el eje de la competencia se construye, de esta forma, con una secuencia textual muy parecida a la de un ensayo científico-técnico. El texto se sitúa pues en una cadena de géneros que, más allá del texto argumentativo y expositivo, está compuesta por una secuencia textual instructiva, típica del género legislativo y normativo, que indica la función deóntica de ERT. En efecto, la tesis final de la secuencia argumentativa se caracteriza por este tipo de secuencia, al producirse una serie de recomendaciones (10) particulares, con temáticas delimitadas, que implican acciones normativas.

En 2010 hemos visto que la posición de la Comisión Europea cambia en función de nuevas estrategias de legitimación que emprende como actor político protagonista, en un contexto que coyunturalmente es demasiado influenciado por el evento Crisis.

En este cuadro la Comisión se encuentra accountable no sólo respecto a los gobiernos nacionales (poliárquica), sino también respecto a la opinión pública. La estructura genérica de Europa 2020 se construye a sí misma con base en estas cuestiones: una cadena continua de géneros que alternan el texto argumentativo, el expositivo y el instructivo en un ejercicio continuo de intergenericidad. A nivel macroestructural podemos identificar dos líneas argumentativas principales: una que desarrolla la temática Europa 2020 como estrategia de crecimiento heredera de Lisboa 2000 (Secuencia 1) y otra que desarrolla la temática Europa 2020 como "estrategia creíble de salida de la crisis" (Secuencia 2). La Secuencia 1 delimita nuestra muestra: está compuesta también por una secuencia expositiva similar al genero de ensayo científico. 


\section{Gráfico 3}

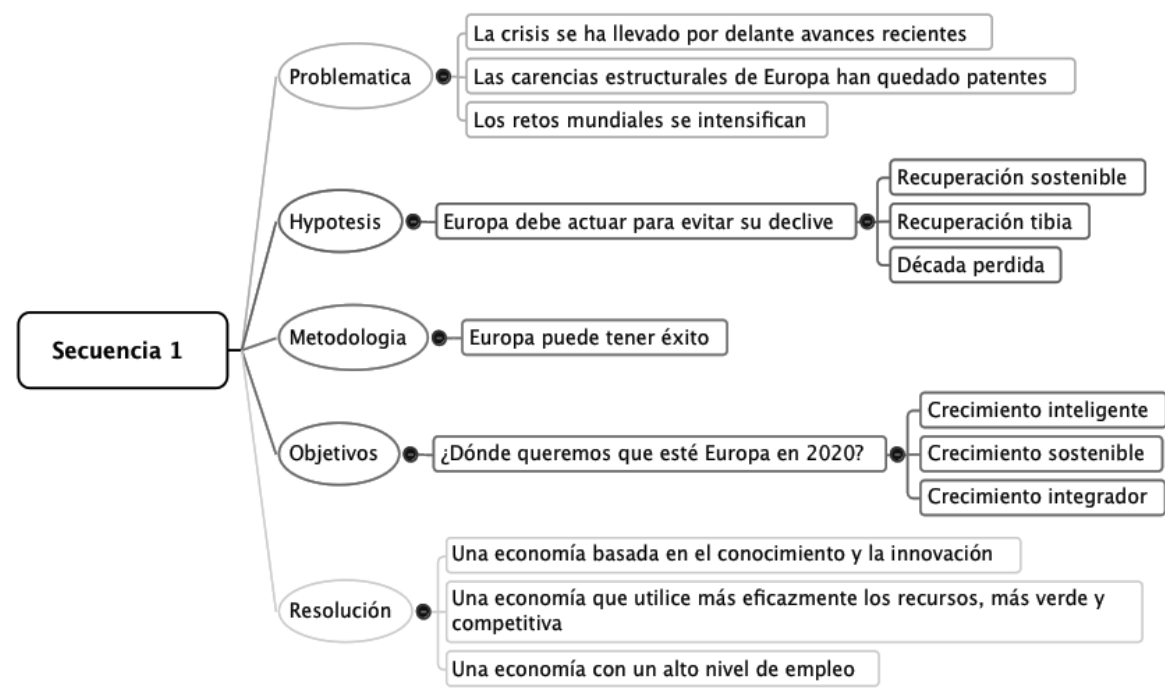

Mientras tanto en 2010, también ERT lanza su estrategia a largo plazo para Europa (ERT, 2010). En esta, tal y como evidenciamos, es predominante la función deóntica del lenguaje, mientras que se queda subordinada la función epistémica. Este sentido de jerarquización funcional se construye también a nivel genérico, mediante una cadena de tipologías textuales. En particular, tal como evidenciamos en el grafico, a un nivel macro el texto presenta características expositivas: 


\section{Gráfico 4}

La visión de ERT en vías de una Europa competitiva en el 2025

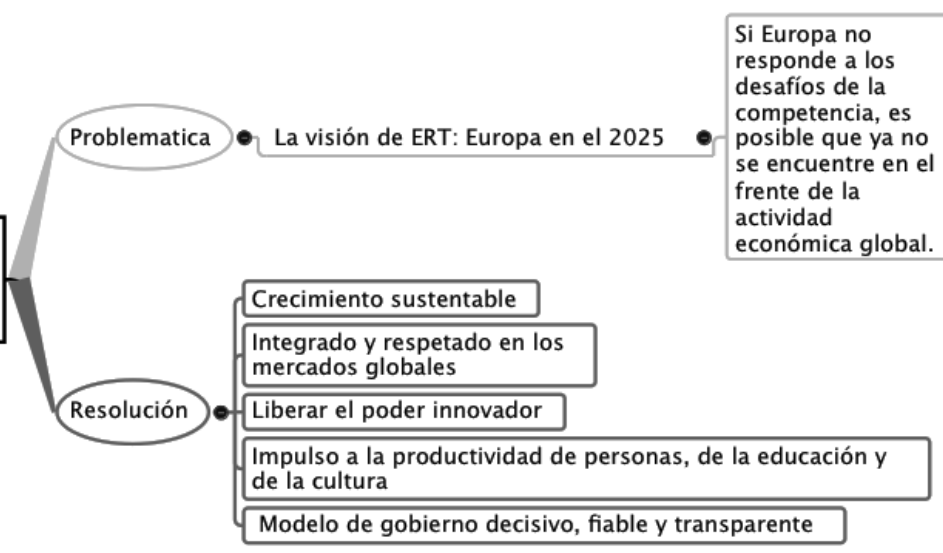

\section{Unidad en Diferencias (Coherencia e Intertextualidad)}

Debemos estar en condiciones de asumir que los distintos argumentos ofrecidos por el tecnocorporativismo, para imponer acciones a los gobiernos y fundamentar su política económico-social, forman una unidad a la que es posible asignar coherencia. Con el concepto de orden del discurso (Fairclough, 1989, p. 28) entendemos cómo operan las referencias interdiscursivas, puesto que están constituidas por las convenciones asociadas a las instituciones de la gobernanza europea y las prácticas sociales del tecnocorporativismo. Por ello, el uso del discurso tecno-científico contribuye a construir una imagen $\mathrm{y}$ un ethos que se revelan estratégicos no solo por las reformas y acciones propuestas sino, sobre todo, por los actores productores de dichas acciones. Las convenciones del discurso tecno-científico están así presentes en los textos: se usan palabras técnicas y específicas, se realizan muchos procesos por medio de nominalizaciones y no de verbos (Maniglio, 2015) y, como hemos visto en el último apartado, con frecuencia la interdiscursividad consiste en mezclar convenciones de distintos géneros.

Esta intergenericidad implica un modo específico de producción, distribución y consumo de los textos: desde el punto de vista de la producción los informes y documentos que componen la muestra son productos 
colectivos; la relevancia de los textos se consigue al construir receptores que se identifiquen con los temas principales, porque tienen/comparten las mismas necesidades, es decir, necesidades colectivas. Las estructuras genéricas de los textos implican una serie de suposiciones implícitas (Fairclough, 1989, p. 202) de que "algunos eventos naturales" son socialmente arriesgados, construyendo una posición interpretativa de/con la opinión pública para hacer frente a estas problemáticas. Las soluciones del problema deben proceder de los actores (tecnocorporativismo) en los que se puede confiar desde un punto de vista de las competencias poseídas. Al utilizar secuencias textuales expositiva-instructivas, típicas de los ensayos científicos, por ejemplo, hemos visto cómo se intenta establecer una relación entre el receptor y el productor, similar a la existente entre los especialistas y la opinión pública. En segundo lugar, haremos una distinción respecto a la interdiscursividad (o intertextualidad constitutiva) y nos ocuparemos de explotar la categoría de la intertextualidad manifiesta, por la cual en un texto se recurre explícitamente a otros textos específicos, para explicar el proceso de producción; pero también para comprender cómo un texto puede ser interpretado desde un punto de vista coherente (Fairclough, 1992, p. 81; Cook, 1994, p. 171; Luzón, 1997). El cuadro global del contexto intertextual del conjunto de los textos objeto de análisis evidencia así una clara lógica y secuencia.

\section{Gráfico 5}

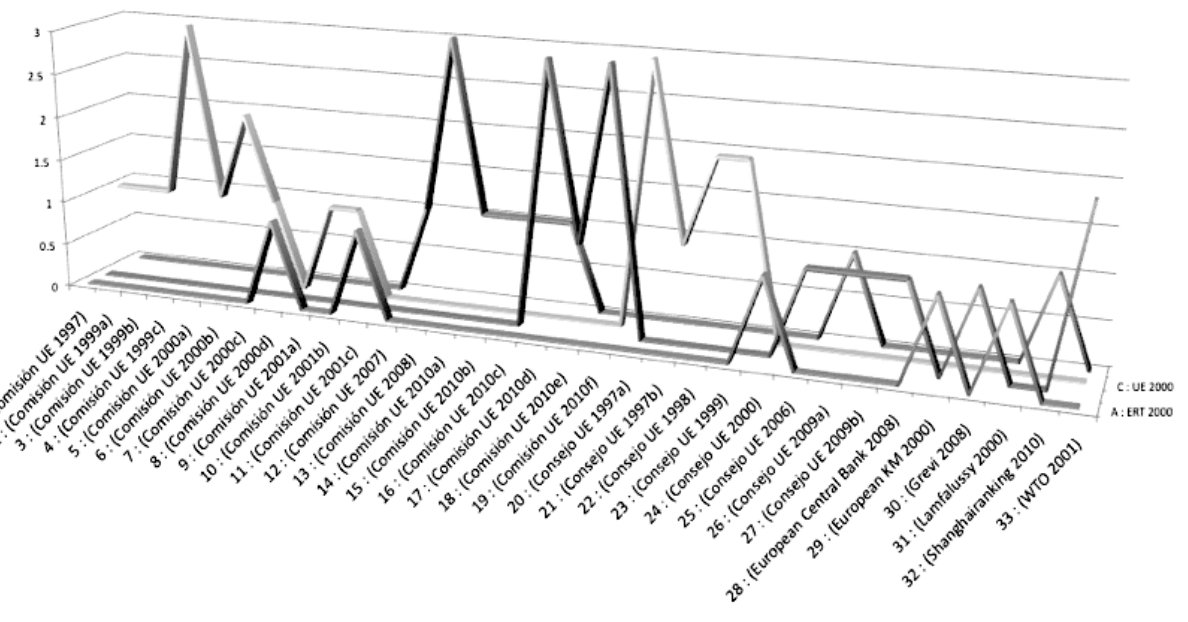

$\equiv$ A : ERT $2000 \quad \equiv$ B: ERT $2010 \quad$ C:UE $2000 \quad$ D : UE 2010 
Al incorporar determinados elementos intertextuales explícitos en un texto, el autor construye de facto una posición para el sujeto que interpretará el texto. Por tanto, el concepto de intertextualidad es básico para comprender cómo un sujeto percibe la coherencia de un escrito. En términos de producción, la perspectiva intertextual acentúa el carácter histórico de los textos y los sitúa de forma coherente en las funciones coyunturales: de acuerdo a cómo se constituyen en cuanto "cadenas de comunicación verbal" existentes (Bakhtin, 1986, p. 94) con textos previos a los cuales responder/relacionarse. Es decir, la interpretación de la intertextualidad consiste en dos fases: percepción del pre-texto, e integración del pre-texto en el significado global del texto. Parte del conocimiento que usamos en este proceso de interpretación se refiere, entonces, al contexto intertextual de nuestro corpus, o sea el conjunto de textos previos que se están relacionando con los textos actuales. Vemos solo unos ejemplos que nos ayudan a interpretar cómo los productores de los textos (Consejo y Comisión UE, ERT) usan los fragmentos evidenciados en el contexto intertextual o convenciones de otros tipos de textos con una intención determinada. En principio, analizamos la desviación intertextual ${ }^{14}$ del texto del Consejo Europeo de Lisboa (UE, 2000), evidenciando la inclusión y transformación de varios segmentos de pre-textos.

\section{Gráfico 6}

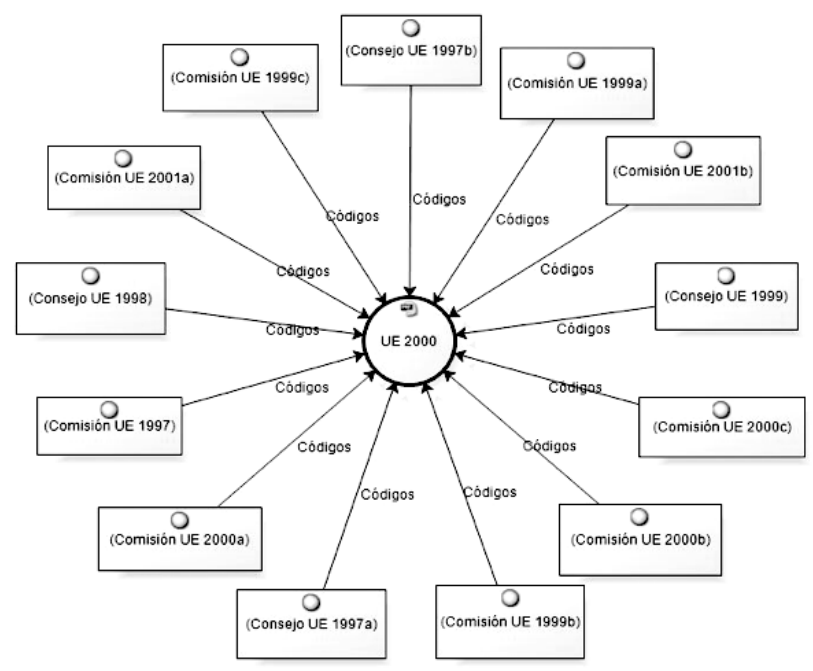

14 Según Plett (1991), "la intertextualidad de un texto se logra alterando un pre-texto o segmento de pre-texto. En realidad, el pre-texto se reconstruye y se le da un nuevo significado. El resultado de esta transformación se define como «desviación intertextual». La transformación de un segmento de pre-texto para incluirlo en otro texto puede ser de varios tipos: adición, sustracción, sustitución, permutación, y repetición" (Luzón 1997: 140). 
Podemos percibir claramente que este texto ha sido construido a partir de varios textos previos que aparecen en los informes, decisiones y recomendaciones tanto del Consejo como de la Comisión. El reconocimiento de estas referencias intertextuales nos posibilita la interpretación del texto dentro de un continuum político que delinea la revolución permanente del tecnocorporativismo europeo, situando históricamente (continuum histórico) acontecimientos que - como hemos visto- de otro modo quedarían en el plano descriptivo como "eventos naturales". Vemos cómo unas referencias explícitas conforman un continuum histórico según la lógica de la repetición de textos previos en el texto principal, dado que se recalcan decisiones políticas ya adoptadas para que sean reforzadas y/o reformadas con el objetivo de obtener un resultado performativo en la nueva agenda política que se propone:

16. Es necesario actuar rápidamente para culminar el mercado interior en determinados sectores y mejorar los resultados insuficientes en otros a fin de velar por los intereses de empresas y consumidores. Para obtener un máximo rendimiento de la liberalización del mercado, es asimismo fundamental disponer de un marco eficaz para llevar a cabo la actual labor de revisión y mejora, basada en la Estrategia del Mercado Interior aprobada por el Consejo Europeo de Helsinki. (IIUE 2000> Referencia 1\ interext Consejo UE 1999).

28. El proceso de Luxemburgo, basado en la elaboración de directrices de empleo a nivel comunitario y su plasmación en planes de acción nacionales de empleo, ha permitido que Europa reduzca sustancialmente el desempleo. (IIUE 2000> Referencia 3\ interext Consejo UE 1997)a2.

En el caso del informe Acciones para la competitividad a través de la Economía del Conocimiento en Europa de ERT (2000), las representaciones de los discursos previos sirven con frecuencia para incorporar el testimonio de otros grupos, decreta así la alianza de clase tecno-corporativa y otorga al discurso una pretensión de cientificidad.

Vemos en el siguiente ejemplo algunas referencias intertextuales que siempre, según la lógica de la repetición, pueden ser interpretadas para este propósito:

Como una organización cuya prioridad clave es la de fortalecer la competitividad europea, el ERT está apoyando afectuosamente la estrategia de Lisboa del Consejo Europeo. Sin embargo, teniendo en cuenta la crisis técnica y las necesidades urgentes de la 'nueva Europa' el ERT opina que es necesario un enfoque más riguroso y un progreso más acelerado en cuatro tareas fundamentalmente importantes que estuvieron presentes en las conclusiones de Lisboa, con varios grados de énfasis. Estos cometidos son: 
- $\quad$ el replanteamiento de los sistemas nacionales de educación para que habiliten a todos los individuos la adquisición de nuevas técnicas necesarias durante un proceso de formación permanente;

- fomentar a los empresarios a actualizar las técnicas de la plantilla existente.

- Crear una atmósfera propicia para la innovación y el espíritu empresarial.

- $\quad$ Reinventar el gobierno para la era online ( $\backslash E R T 2000>$ Referencia $1 \backslash \backslash$ interext Consejo UE 2000).

La Mesa Redonda Europea de Empresarios Industriales recibe con buen gusto la comunicación de la Comisión titulada 'Desarrollando el Potencial de la Unión Europea: Consolidando y Extendiendo la Estrategia de Lisboa'. En ella se encuentran recomendaciones para acciones que aún tienen que ser aceptadas por el Consejo Europeo en Estocolmo y que son de primordial importancia para la competitividad europea (\IERT 2000> Referencia 1\ interext Comisión UE 2001c).

Estas relaciones intertextuales consiguen el objetivo persuasivo para el que han sido diseñadas, ya que colocan a los receptores/analistas frente a medidas indiscutibles, que son directamente relevantes (carácter de cientificidad); así como ya establecidas (objetividad) para la resolución de las problemáticas que, tal y como hemos visto, se representan como eventos naturales y críticos. La práctica hegemónica del tecnocorporativismo indica claramente una reducción/ampliación (siempre dialéctica) de los posibles, que no implica la desautorización de las otras posibilidades, sino más bien la asunción de las posibilidades alternativas. La autorización y legitimación de los agentes implicados constituyen así la dirección tecno-intelectual y moral que se construye con las lógicas particulares de carácter tecno-científico, políticoético y económico.

\section{Conclusiones}

Hemos considerado los procesos de gobernanza global en tanto que políticas mundiales en contraposición con la tradicional definición de relaciones internacionales (Dingwerth \& Pattberg, 2006). No se trata de pensar la gobernanza global en los términos de un discurso revisitado del orden y la regulación (Brand, 2005). Debemos subrayar qué procesos políticos determinados están en la base de la construcción de las formas de gobernanza internacionales. En el caso de la UE estos son identificables históricamente con el proceso tecnocratización de los Estados, el cual se dio en el contexto de las 
políticas post-Lisboa, proceso que no abarcó solo los aspectos organizacionales o las capacidades de gestión, sino también los aspectos ideológicos y de racionalización (Radaelli, 1999a; 1999b; 2000).

En la construcción de la legitimidad se ha ido debilitando progresivamente la importancia del sentido específicamente intelectual de la ideología (disputas de ideas), en favor de los procesos técnicos de resolución de problemas. Con la desintelectualización (Balsa, 2006) de la hegemonía no se genera consenso respecto a una visión del mundo univoca, sino mas bien respecto a que grupo particular (o función particular) debe conducir. Es la dirección tecnopolítica, o sea su grado de capacidad de imponer y actuar una particular visión del mundo. Una dirección mediada, porque -aunque supone la centralidad del consenso y de la aceptación en los procesos hegemónicos- no implica una visión idealista o naif que niegue las determinaciones más profundas del poder; fundamentalmente porque el consenso, e inclusive la "voluntad", son socialmente construidos a través de múltiples procesos de socialización que nos enseñan lo que "debemos" querer (Foucault, 1977). El discurso tecnopolítico, al interior de las prácticas de legitimación de la gobernanza en la UE, nos indica qué prácticas ideológicas han mutado de posición: no se manifiestan más como centrales en lo que pensamos hacer (desintelectualización de la hegemonía), sino en lo que hacemos pensando (en nuestra disposición en la división del conocimiento, de la comunicación y del trabajo; en las relaciones de producción). Nuestras convicciones íntimas nacen siempre en forma de nuevos rituales de los cuales la ideología aún se sirve, y que corresponden cada vez más a nuevos dispositivos de medición y control de un Estado Integral guiado por la gobernanza europea (Lazonick \& O’Sullivan, 2000). 


\section{Referencias bibliográficas:}

Bakhtin, M. M. (1986). Marxismo e Filosofia da Linguagem: problemas fundamentais do método sociológico na ciência da linguagem. São Paulo: Hucitec.

Balsa, J. (2006). Las tres lógicas de la construcción de la hegemonía. Theomai: estudios sobre sociedad, naturaleza y desarrollo, (14), 2-36.

Brand, U. (2005). Order and regulation: Global Governance as a hegemonic discourse of international politics? Review of International Political Economy, 12(1), 155-176.

Chouliaraki, L., \& Fairclough, N. (1999). Discourse in Late Modernity: Rethinking Critical Discourse Analysis. Edinburgh University Press.

Coutinho, C. N. (2011). L'epoca neoliberale e l'egemonia della piccola politica. En Dialettica, storia e conflitto. Il proprio tempo appreso nel pensiero (pp. 279-293). Napoli: La Scuola di Pitagora.

Dingwerth, K., \& Pattberg, P. (2006). Global Governance as a Perspective on World Politics. Global Governance, 12(2), 185-203.

Fairclough, N. (1989). Language and power. London: Longman.

Fischer, F. (1990). Technocracy and the Politics of Expertise. New York: Sage Publications.

Fischer, F., \& Forester, J. (1993). The Argumentative Turn in Policy Analysis and Planning. Duke University Press.

Franquesa Strugo, A. M. (2002). Breve reseña de la aplicación del análisis crítico del discurso a estructuras léxico-sintácticas. Onomázein [artículo de revista], (7), 449-462.

Gerstenberg, O., \& Sabel, C. F. (2002). Directly-deliberative polyarchy: an institutional ideal for Europe? En Good governance in Europe's integrated market (pp. 289-341). New York: Oxford University Press.

Halliday, M. A. K. (1985). An introduction to functional grammar. London; Baltimore, Md., USA: E. Arnold.

Halliday, M. A. K., \& Hasan, R. (1991). Language, context, and text: aspects of language in a social-semiotic perspective. Oxford University Press.

Innerarity, D. (2011). La democracia del conocimiento: Por una sociedad inteligente. Barcelona: Grupo Planeta Spain.

Jameson, F. (1991). Postmodernism Or, The Cultural Logic of Late Capitalism. Duke University Press.

Lazonick, W., \& O'Sullivan, M. (2000). Maximizing shareholder value: a new ideology for corporate governance. Economy and Society, 29(1), 13-35.

Lirola, M. M. (2007). Aspectos esenciales de la gramática sistemática funcional. Alicante: Publicaciones de la Universidad de Alicante. 
Luzón, M. J. (1997). Intertextualidad e interpretación del discurso. Epos, 13, $135-149$.

Majone, G. (1996). Temporal consistency and policy credibility: why democracies need non-majoritarian institutions. Temporal consistency and policy credibility: why democracies need non-majoritarian institutions, 96 (57).

Maniglio, F. (2015). To lead without governing in the knowledge society: The enlightened despotism in European techno-corporative discourse. Discourse \& Society, (27), 1.

Maniglio, F. (2016). La subsunción del saber: la transformación de la Universidad en la época del Capitalismo Cognitivo. En F. Sierra Caballero, Capitalismo Cognitivo y Economía Social del Conocimiento. La lucha por el Código. Quito, Ecuador: Ed. Ciespal.

Marks, G., Scharpf, F. W., Schmitter, P. C., \& Streeck, W. (1996). Governance in the European Union. New York: Sage.

Matsuura, K. (Ed.). (2005). Hacia Las Sociedades Del Conocimiento: Informe Mundial de la Unesco. Unesco.

Mattelart, A., \& García Castro, Antonia. (2006). Sociedad del conocimiento, sociedad de la información, sociedad de control. Culture and Conflits.

Plett, H. F. (1991). Intertextuallity. New York: de Gruyter.

Radaelli, C. M. (1999a). Idee e conoscenza nelle politiche pubbliche europee: tecnocrazia o politicizzazione? Rivista italiana di scienza politica, (3).

Radaelli, C. M. (1999b). Technocracy in the European Union. Bruxelles: Routledge.

Radaelli, C. M. (1999c). The public policy of the European Union: whither politics of expertise? Journal of European public policy, 6 (5), 757-774.

Radaelli, C. M. (2000). Whither Europeanization?: Concept stretching and substantive change. European Integration online Papers (EIoP), (4), 8.

Ramalho, V., \& Resende, V. (2011). Análise de discurso (para a) crítica: $O$ texto como material de pesquisa (Vol. 1). Campinas, SP: Pontes Editores.

Restakis, J. (2015). Institucionalidad: sociedad del conocimiento, economía social y partner state. En D. Vila-Viñas \& X. E. Barandiaran (Eds.), Buen Conocer - Flok Society. Modelos sostenibles y políticas públicas para una economía social del conocimiento común y abierto en el Ecuador (pp. 479-550). Quito: Iaen-Ciespal.

Rubio, E. (2003). Saber y poder: la cuestión democrática en la sociedad del conocimiento. Fundación Friedrich Ebert en Uruguay.

Ruiz, M., \& Sylvia, A. (2005). La política como discurso en las raíces de la teoría de la praxis. En VII Congreso Nacional de Ciencia Política. Córdoba: Saap y Facultad de Ciencia Política y Relaciones Internacionales de la Universidad Católica de Córdoba. 
Scharpf, F. W. (1997). Games Real Actors Play: Actor-centered Institutionalism In Policy Research. Boulder: Westview Press.

Scharpf, F. W. (1999). Governing in Europe: Effective and Democratic? Oxford: Oxford University Press.

Scharpf, F. W. (2000). Institutions in Comparative Policy Research. Comparative Political Studies, 33(6-7), 762-790.

Serrano, A., \& Crespo, E. (2002). El discurso de la Unión Europea sobre la sociedad del conocimiento. Reis, (97).

Sierra Caballero, F. (2006). Políticas de Comunicación y Educación: Crítica y desarrollo de la Sociedad del Conocimiento. Barcelona: Gedisa.

Van Dijk, T. (1999). Ideologia - Una Aproximacion Multidisciplinaria. Gedisa Barcelona.

Van Eemeren, F. H. (1997). Argumentation. En Discourse as Structure and Process (Vol. 1). London: Sage. 
